\title{
Real convergence in Central and Eastern Europe. A comparative analysis of countries and regions
}

\author{
Ana-Maria HOLOBIUC \\ Bucharest University of Economic Studies, Bucharest, Romania \\ anamaria.holobiuc@yahoo.com
}

\begin{abstract}
One of the fundamental pillars of the European Union aims the convergence of economic performances between countries and regions. This objective has proved to be increasingly difficult to achieve with the expansion of the regional group towards the Central and East of the continent. The aim of this paper is to study real convergence in the New Member States from Central and Eastern Europe, by taking into consideration the evolution of GDP per capita between 2000 and 2018. In this respect, we have conducted a comparative analysis between countries and regions using $\beta$-and $\sigma$-convergence. By applying cross-sectional regressions, we have identified a strong relationship between the initial level of income of the Central and Eastern European countries and the subsequent growth rates, the average catching-up speed reaching 3.6\%. Moreover, $\beta$-convergence was accompanied by a reduction of income divergences between Central and Eastern European Members. In contrast, our analysis suggests a weaker process of convergence between regions compared to countries, the convergence rate reaching $1.7 \%$ per year. Furthermore, by studying the intra-national patterns, we have illustrated that the capital regions have consolidated their relative position in the majority of the Central and Eastern Member States to the detriment of the other territorial units. Consequently, the paper suggests that convergence across countries was accompanied by an increase of intra-national disparities between regions in Central and Eastern Europe.
\end{abstract}

Keywords: European Union, Central and Eastern Europe, real convergence; NUTS 2 regions; $\beta$-convergence; $\sigma$-convergence.

\section{Introduction}

The establishment of the European Economic Community in the second half of the last century has proved to be a successful project of six visionary countries that has fundamentally changed the history of the European continent. Soon after the first initiatives of regional cooperation, more and more European countries adhered to the regional group's goals and principles. Consequently, the European project evolved from a customs union to an economic and monetary union, comprising nowadays under the same common values the twenty-seven Member States. Despite the recent regional and global turmoil, the European Union has proved its ability to manage economic and financial, social, and sanitary crises. However, one of the objectives that have not been accomplished so far aims the convergence of the economic performances between countries and regions. Although the European leaders stated since the creation of the European Economic Community the objective to reduce the development gaps between regions, the accession of the Southern and Central and Eastern European (CEE) countries have called into question the capacity of the European Union to achieve this goal. Consequently, increasing convergence between countries and regions has become a primary objective in the decision-makers' agenda, mainly with the expansion towards the East of the continent.

The main purpose of this paper is to study real convergence in the European Union, by bringing to the forefront the evolution that took place between 2000 and 2018 in Central and Eastern Europe. In this respect, we have tried to identify if the CEE economies are catching up or 
by contrast as falling behind by conducting a comparative analysis between countries and regions. The methodological tools implied $\beta$ - and $\sigma$-convergence, which were developed by Barro \& Sala-i-Martin $(1990,1992)$ in order to study the convergence patterns. $\beta$-convergence supposes that the initially poorer economies experience higher growth rates than the developed ones, while $\sigma$-convergence studies if income differentials decrease over time. In the second section of the paper, we have examined the intra-national convergence/divergence patterns in CEE, by taking into consideration the evolution of income per capita of the regions compared to the national average. Our study suggests that convergence is stronger between CEE countries than regions. In this respect, the catching-up speed between countries was on average 3.6\%, and the relationship between the initial income per capita and the subsequent growth rates was strong. In contrast, the catching-up speed between the CEE regions was only $1.6 \%$ between 2000 and 2018. The analysis of the intra-national patterns offers an explanation for the weak convergence identified in the CEE regions: the wealthy capital regions have predominantly improved their relative position between 2000 and 2018, while the other territorial units have lagged behind. Consequently, the analysis suggests that convergence between CEE countries has been accompanied by an increase in intra-regional disparities.

\section{Literature review}

The topic of real convergence has become increasingly studied with the subsequent waves of enlargement of the European Union and the advancement of the integration process from a customs union to an economic and monetary union. Particularly, researchers focused on the CCEE group, trying to respond to the question if these New Members are catching up or lagging behind the developed European countries. By using quantitative and qualitative methods, researchers have mainly focused on income, as a key indicator for real convergence. Moreover, while some studies brought to the forefront the evolution that took place at a national level, other studies focused on regions. Convergence across countries was studied by Vojinović et al. (2009), Dobrinsky \& Havlik (2014), Matkowski et al. (2016), Alcidi (2018 a) Rapacki and Próchniak (2019) analysts founding evidence in favor of convergence in CEE. Vojinović et al. (2009) identified a catching-up process in the CEE countries (8) in the second half of the ' 90 s and at the beginning of the third millennium. According to analysts, the convergence rate was 4.2\% in 1992 and 2006, but the highest performance was experienced between 2002 and 2006, reaching 7.0\% - 9.6\%. Similarly, Matkowski et al. (2016) illustrated that the New CEE Member States recorded annual growth rates reaching 3.2\% between 1993 and 2015, while in the Old Members the convergence rate reached only 1.5\%. Rapacki \& Próchniak (2009) studied real convergence in the New and Old Members, founding evidence in favor of the neoclassical growth model. Consequently, the CEE Members experienced higher growth rates than the developed ones between 1996 and 2007. Moreover, the analysts pointed out that the income differences decreased in both at the aggregate and subgroup level ( $\sigma$-convergence).

Similarly, Rapacki \& Próchniak (2019) studied income convergence between New and Old Members between 1995 and 2005. Analysts noted that the efforts to internalize the acquis communautaire and accession to the European Union have created similar economic, institutional, and social structures in the CEE region. Rapacki \& Próchniak found evidence to support the hypothesis of conditional convergence, both at the aggregate level and between the CEE group and the Old Members. Consequently, analysts identified a convergence rate of 2.2\% between 1995 and 2015, the leaders of the convergence process being the Baltic States, which recorded annual growth rates of $4.5 \%-5 \%$. In the same line, Dobrinsky \& Havlik (2014) studied real convergence in the 
CEE countries during the transition period and after the accession to the European Union, founding evidence in favor of the $2 \%$ law of convergence. At the same time, Dobrinsky \& Havlik illustrated that the New Member States form a convergence club, with similar features and convergence patterns.

Apart from studying convergence across countries, analysts have also taken into consideration the evolutions that occurred at a regional level. One of the most important pillars of the European Union, especially with the successive stages of enlargement, has proved to be cohesion between the Member States and the component regions. The goal of reducing interregional disparities has been established in the Preamble to the Treaty of Rome (1957) and has become a primordial goal with the expansion of the European Union towards the East of the continent. Magrini (1999) analyzed income convergence in the European regions between 1979 and 1990, taking into consideration 122 major Functional Urban Regions. In this respect, the analyst identified rather divergent trends between European regions. Similarly, Goecke \& Hüther (2016) identified significant discrepancies between NUTS 3 region, mainly in countries such as Germany and Italy. At the same time, Goecke \& Hüther found evidence to support the $\beta$-convergence hypothesis, namely that the poorer regions of the European Union experienced higher growth rates compared to the more developed ones. Regarding $\sigma$-convergence, the analysis carried out by Goecke \& Hüther suggests that in the period 2000-2009, the coefficient of variation between the regions at NUTS 3 level had a predominantly downward trend, subsequently increasing. According to the analysts, a number of factors influence the divergent economic performance at the regional level, such as the proximity to national borders, the receipt of subsidies, the business structure of the economy, the quality of infrastructure, and investment in research and development.

From another perspective, Alcidi et al. $(2018 \mathrm{~b})$ conducted a comparative analysis between regions and countries between 2000 and 2015, taking into consideration the evolution of GDP per capita. In this respect, the analysts illustrated that the level of GDP per capita at the regional and national level had an upward trend during the analyzed time span, and at the same time, that income discrepancy decreased. The main winners of the convergence process were the CEE states and regions, which recorded higher growth rates compared to the Community's average. Despite these global trends, a detailed analysis of the regions and countries they belong to has led to surprising conclusions. Alcidi et al. highlighted that in the case of the CEE countries, capitals experienced higher GDP per capita growth rates than the Community's average. However, the accelerated process of convergence of capital regions in countries such as Bulgaria, the Czech Republic, Poland, Romania, and Hungary determined an increase of internal disparities, as the other territorial units were lagging behind. In contrast, in the regions of the developed countries of northwestern Europe, analysts have identified a trend of convergence, especially in Austria and Germany, where the capital regions have lost their relative advantage compared to the other geographical regions.

Similarly, Kolev (2012) illustrated that the European Union is divided between the less developed regions of CEE and the South of the continent and the less developed in the North of the continent. Despite the progress achieved during 2000 and 2007 and the higher growth rates experienced by the New Member States, the economic crisis has had a negative impact on the progress achieved in the previous period. However, at the aggregate level, the analyst identified an increase in economic cohesion in 2009 compared to 2007, as more regions reached the European average. The analyst also pointed out that Bulgaria, Poland, and Romania recorded higher growth rates than the European Union's average. Bourdin (2015) studied convergence at the regional level between 1995 and 2007, presuming that that geographical location influences the speed of 
economic integration in CEE. The analyst demonstrated that the process of regional integration within the CEE countries is heterogeneous, the geographical location having a defining role in influencing the convergence patterns. At the same time, Bourdin identified that a large number of regions on the borders of the former Iron Curtain are experiencing significant convergence processes, forming a convergence club in the region.

\section{Methodology}

In order to test the assumptions of the study, we have used the instruments developed by Barro \& Sala-i-Martin $(1990,1992): \beta$ - and $\sigma$-convergence. $\beta$-convergence aims a negative relationship between the initial level of income and the subsequent growth rates, as stated by the neoclassical growth model exponents (Solow, 1956, Swan, 1956). According to the neoclassical model, the poorer economies experienced higher growth rates taken into consideration the higher profitability of the production factors. $\beta$-convergence was complemented by another instrument $\sigma$-convergence - which studies if income differentials between economies diminish over time. Barro and Sala-i-Marin $(1990,1992)$ noted that " $\beta$-convergence is a necessary, but not a sufficient condition for $\sigma$-convergence”. Consequently, convergence is not an automatic process and higher growth rates will not guarantee the reduction of income disparities.

In order to estimate $\beta$-convergence for the CEE countries and regions, we have employed cross-sectional simple regressions, taking as a dependent variable the average GDP growth rate between 2000 and 2018. Taking into consideration the assumptions of the model, the independent variable was the income per capita in the initial year. In addition to $\beta$-convergence, $\sigma$-convergence has been estimated using a simple linear regression, where the dependent variable was the standard deviation of the natural logarithm of the GDP per capita and the independent one the time factor. Data aiming at the evolution of GDP per capita for countries and regions at NUTS 2 level was obtained from Eurostat Database. Although at the moment of the study, data for countries was available until 2019, information regarding the GDP per capita of the regions at NUTS 2 level was available only until 2018. Consequently, for comparative purposes, we have chosen to study the timespan 2000 and 2018.

In order to study $\beta$-convergence at the national and regional level, we have employed a simple cross-sectional regression, based on the following formula:

$$
\frac{1}{T} \ln \left[\frac{y_{i t}}{y_{i 0}}\right]=a+\alpha_{1} \ln \left(y_{i o}\right)+\varepsilon
$$

$y_{i t}=$ GDP per capita of country or region $i$ in $t$;

$y_{i 0}=$ GDP per capita of economy $i$ in 2000;

$\mathrm{T}=$ period of time;

$\alpha=$ constant;

$\varepsilon=$ error term.

The speed of convergence was computed as follows:

$$
\beta=-\frac{1}{T} \ln \left(1+\alpha_{1} T\right)
$$

The number of years that are necessary in order to reach the halfway of the transition period towards equilibrium was determined as follows: 


$$
t^{*}=\frac{\ln 0.5}{\beta}
$$

In order to study if income divergences between countries and regions decreased during the analyzed time span, we have initially calculated the standard deviation:

$$
\sigma \log _{t}=\sqrt{\left(\frac{1}{n}\right) \sum_{i=1}^{N}\left[\log \left(y_{i t}\right)-\log \left(\mu_{t}\right)\right]^{2}}
$$

$y_{i t}=$ GDP per capita of economy $i$ in $t$;

$\mu_{t}=$ the average income in the European Union in $t$.

$\sigma$-convergence was determined based on a simple linear regression, where the dependent variable was the standard deviation, and the independent one the time factor:

$t=1, \ldots, 19$

$$
\sigma \log \left(y_{t}\right)=\alpha_{0}+\alpha_{1} t+\varepsilon
$$

if $\alpha_{1}<0, \sigma$-convergence hypothesis can be validated.

In the second section of our paper, we have tried to study the intra-national convergence/divergence patterns by calculating the relative position of each region compared to the national average. In this respect, we have used the following formula:

$$
\frac{y_{i t}}{y_{i 0}}=a+\alpha_{1} y_{i o}+\varepsilon
$$

$y_{i t}=$ GDP per capita of region $i$ as percentage of national average in $t$;

$y_{i 0}=$ GDP per capita of region $i$ as percentage of national average in 2000;

$\mathrm{T}=$ period of time;

$\alpha=$ constant;

$\varepsilon=$ error term.

\section{Results and discussions}

Figure 1 illustrates the results of $\beta$-convergence for the CEE countries. The negative slope of the trend line confirms the neoclassical growth model assumptions, as the initially poorer members experienced higher GDP growth rates compared to the other countries. Being placed in the upper part of the graph, Romania experienced an average GDP per capita growth rate reaching 7.3\%, being followed by Bulgaria (5.4\%) and the Baltic States. The lowest growth rates in the CEE cluster were experienced by the Czech Republic (3.6\%) and Slovenia (2.8\%), countries with initial income above the subgroup average. 


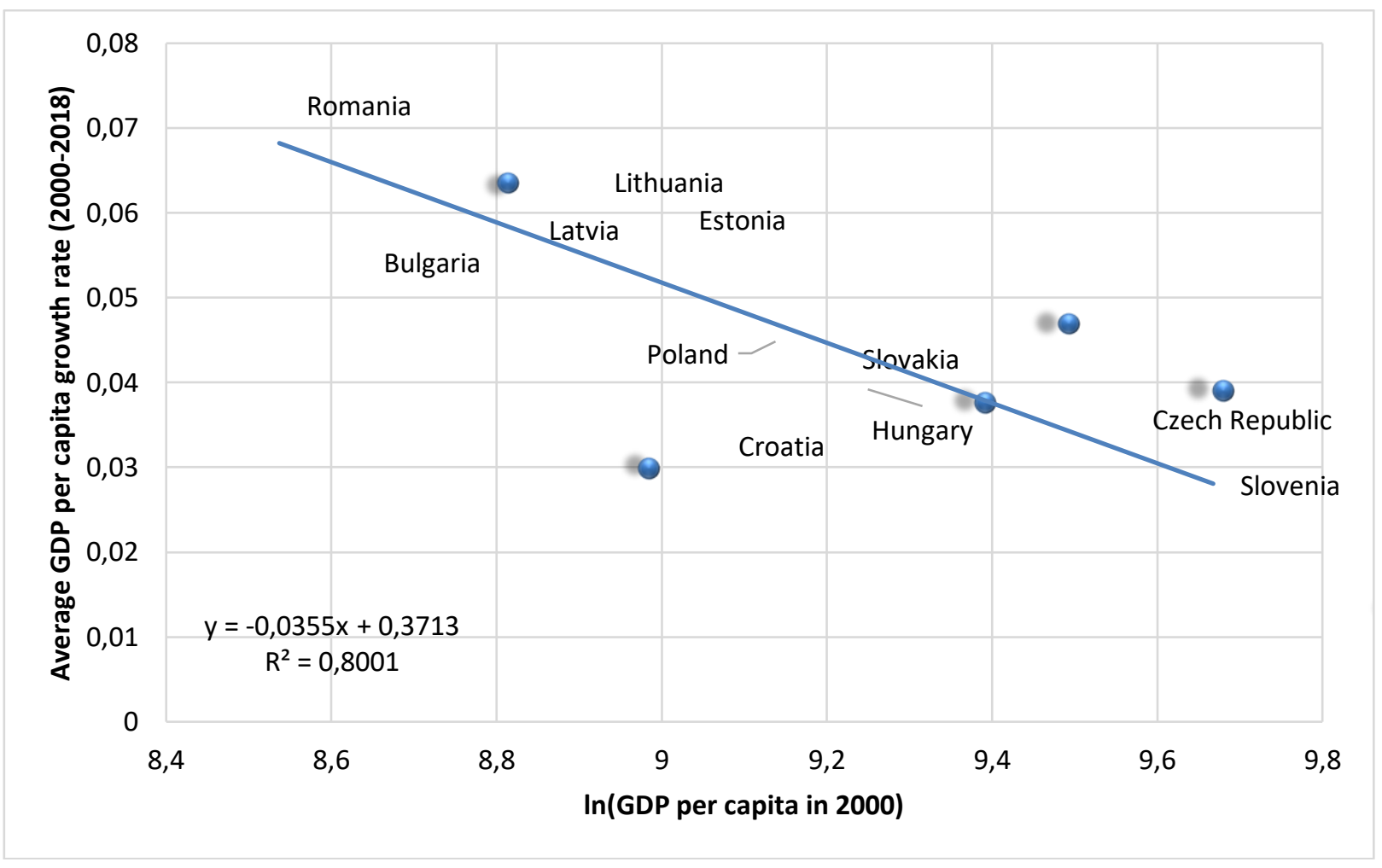

PICBE |

Figure 1. $\beta$-convergence in the Central and Eastern European countries

Source: Author's computation.

The analysis of $\beta$-convergence between countries is complemented by the study of regional convergence. In this respect, figure 2 illustrates the relationship between the initial level of GDP per capita and the subsequent growth rates in the CEE regions at NUTS 2 level. Also, in this case, the negative slope of the trend line confirms that the initially poorer economies experienced higher growth rates during the timespan 2000-2018. The highest growth rates were experienced, as expected, by Romania's regions. Particularly, the capital region - Bucuresti-Ilfov recorded an average growth rate of $7.5 \%$. However, this trend calls into question the neoclassical growth model hypothesis, taking into consideration that this region was the wealthiest at the national level in the 2000s. Similarly, the capital regions from Lithuania (Sostines regions) and Bulgaria (Yugozapaden) recorded above the group's average growth rates, exceeding $6 \%$ per year. The average catching-up speed in the CEE regions was around 3.6\% between 2000 and 2018. The lowest growth rates were experienced by the Czech and Slovenian regions (Severozápad and Vzhodna Slovenija), reaching $2.7 \%$. 


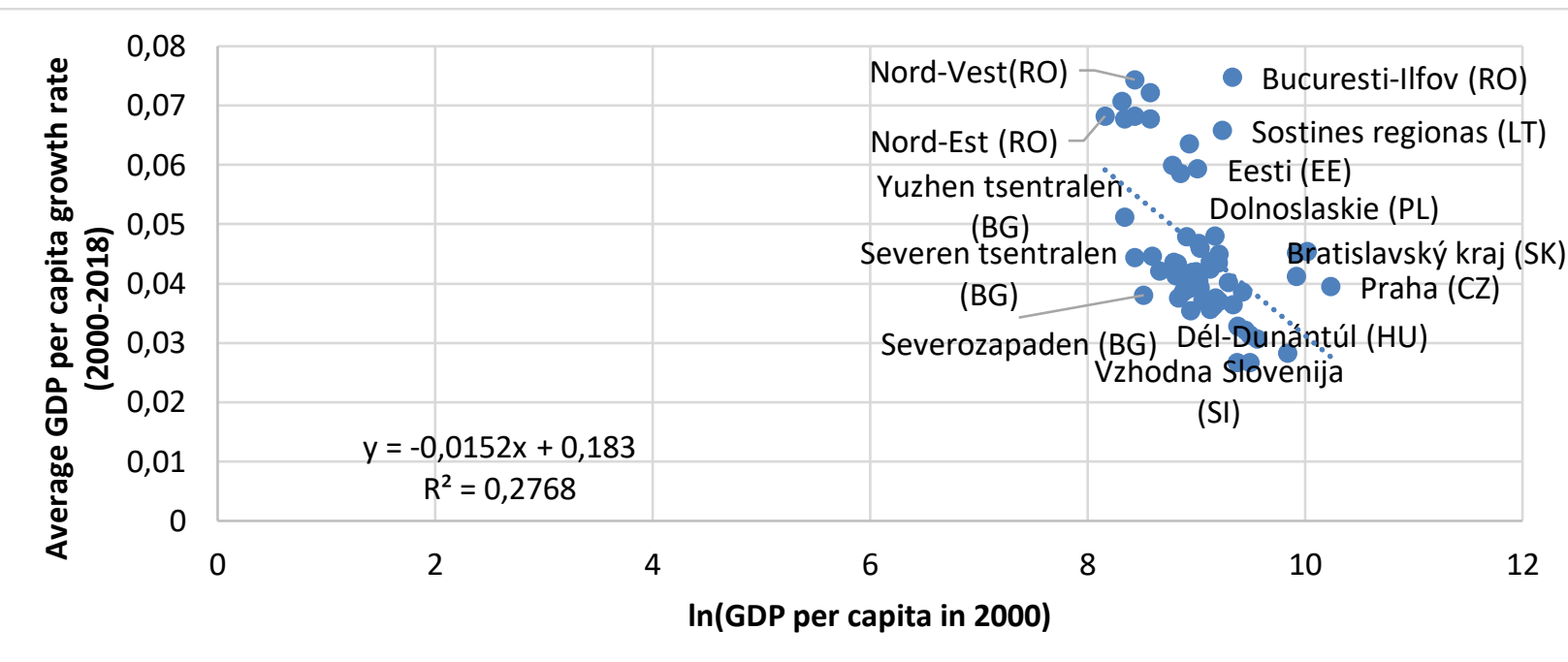

PICBE | 830

Figure 2. $\beta$-convergence in the Central and Eastern European NUTS 2 regions

Source: Author's computation.

In table 1 are comparatively presented the results of $\beta$-convergence for CEE countries and regions. In both cases, the negative sign of $a_{1}$ suggests an inverse relationship between variables. Consequently, the poorer economies experienced higher GDP growth rates than the developed ones. However, the values of the coefficient of variation confirm a strong relationship for CEE countries, but a weak one for regions. This result can be explained by the consolidation of the wealthy capital regions. Based on the values of the $\mathrm{a}_{1}$ coefficient, the estimated convergence speed is $3.6 \%$ for countries and only $1.5 \%$ for regions at NUTS 2 level. Consequently, the CEE countries need 19 years to reach the hallway of the transition period to the state of equilibrium, while the regions are almost 46 . This comparative analysis suggests that convergence between CEE countries improved between 2000 and 2018. By contrast, the negative relationship between variables is less prominent at the regional level. In conclusion, convergence between regions occurred at a slower pace compared to countries between 2000 and 2018.

Table 1. $\beta$-convergence in the Central and Eastern European countries and regions

Dependent Variable: Average GDP per capita growth rate between 2000-2018

\begin{tabular}{|c|c|c|}
\hline \multicolumn{2}{|c|}{ Dependent Variable: Average GDP per capita growth rate between 2000-2018 } \\
\hline & Method: Ordinary Least Squares \\
\hline Observations & Countries (11) & Regions (59) \\
\hline $\boldsymbol{\alpha}$ & $0.3713^{*}$ & $0.1830^{*}$ \\
& $(0.0537)$ & $(0.0294)$ \\
& $(6.9036)$ & $(6.2210)$ \\
\hline GDP per capita in 2000 (a1) & $-0.0355^{*}$ & $-0.0151^{*}$ \\
& $(0.0059)$ & $(0.0032)$ \\
\hline R-squared & $(-6.0018)$ & $(-4.6705)$ \\
\hline Adjusted R-squared & 0.8001 & 0.2767 \\
\hline (convergence speed) & 0.7778 & 0.2640 \\
\hline $\mathbf{t}^{*}$ & 0.0361 & 0.0152 \\
\hline
\end{tabular}

Note: $*$ - p-value $<1 \%$. Standard errors and t-statistics are shown in parentheses. 
The analysis of $\beta$-convergence at the national and regional level has been complemented by $\sigma$-convergence. In this respect, table 2 presents the relationship between the standard deviation and time, determined based on equation 5. The negative sign of $t$ confirms that income disparities decreased between CEE countries and regions. Moreover, the high value of the coefficient of variation (above 90\%) suggests a very strong relationship between variables.

Table 2. $\sigma$-convergence in Central and Eastern European countries and regions

\begin{tabular}{|c|c|c|}
\hline \multicolumn{3}{|c|}{$\begin{array}{c}\text { Dependent Variable: Standard deviation } \\
\text { Method: Ordinary Least Squares }\end{array}$} \\
\hline Observations & National & Regional \\
\hline $\boldsymbol{a}$ & $0.4818^{*}$ & $\left(0.8228^{*}\right.$ \\
& 0.0084 & $(98.6257)$ \\
\hline $\mathbf{t}$ & $(56.8711)$ & $-0.0192^{*}$ \\
& $-0.0128^{*}$ & $(0.0007)$ \\
\hline & 0.0007 & $(-26.2518)$ \\
\hline R-squared & $(-17.3523)$ & 0.9759 \\
\hline $\boldsymbol{\sigma}$-convergence & 0.9465 & 0.9745 \\
\hline
\end{tabular}

Note: $*$ - p-value $<1 \%$. Standard errors and t-statistics are shown in parentheses.

In the second section of our paper, we have tried to study the within-country convergence/divergence patterns in CEE, taking into consideration the regions at NUTS 2 level. The main conclusions are presented below:

- In the case of Bulgaria's regions, the positive slope of the trend line suggests a positive relationship between the initial level of income and the subsequent growth rates. Consequently, the initially more developed territorial units registered higher growth rates than the poor ones. For example, the capital region - Yugozapaden - that in 2000 had a GDP per capita reaching $139 \%$ of the national average registered an improvement of $31 \%$ in income level, while Severozapaden, with an initial level of 92 PPS marked a decrease of $19 \%$.

- Similarly, in the Czech Republic, there has been an exacerbation of regional disparities, so that the capital region, with a GDP per capita representing $200 \%$ of the national average in 2000, experienced an increase of $9 \%$. However, the initially poorest region (Moravskoslezsko), with a GDP per capita of $76 \%$ of the national average, experienced an increase by $10 \%$, while other territorial units, such as Severozápad, with initial income below the national average, worsened the relative position, marking a decrease of $14 \%$.

- In Croatia, the two-component regions performed similarly, with no significant development gaps identified.

- During 2000 and 2018, the income gaps between regions in Hungary raised as a result of the consolidation of the relative position of the capital, Budapest. Among the regions with income below the national average, only Ekszak-Magyarország managed to increase its GDP by $10 \%$.

- In Lithuania, the capital region Sostines regions strengthen its position to the detriment of Vidurio ir vakaru Lietuvos regions. Consequently, the former experienced a GDP per capita of 140 PPS, while the latter an income that represented only $78 \%$ of the national average.

- In Poland, the positive slope of the trend line suggests the existence of a rather divergent process. Consequently, the capital region (Warszawski stoleczny), which registered in 2000 a GDP per capita of 228 PPS, consolidated its leading position in relation to the other territorial units. At 
the same time, Dolnoslaskie, a region with a GDP per capita above the national average in 2000, improved its relative position in relation to other regions, experiencing an increase of almost $10 \%$ in GDP. In contrast, there are also regions with a GDP per capita below the national average (Lubelskie, Swietokrzyskie, Warminsko-Mazurskie) which have to worsen their relative position during the analyzed period.

- In Romania, similar to other CEE countries, the capital region consolidated its leading position between 2000 and 2018, the positive slope of the trend line suggesting the existence of divergence processes. During the first year of analysis, Bucharest-Ilfov had a GDP per capita representing $211 \mathrm{PPS}$, while the other seven component regions were below the national average. Analyzing the trends that occurred in the less developed regions, only the North-West and West managed to record increases in income relative to the national average, while the other territorial units lagged behind.

- Similarly, in Slovenia, the capital region Zahodna Slovenija has strengthened its relative position in respect to Vzhodna Slovenija. Consequently, the income disparities between the twocomponent regions increased between 2000 and 2018.

- In Slovakia, the capital Bratislavský kraj experienced an increase of the income by 3\% maintaining its leading position. Within Slovakia, there were still significant discrepancies between regions in 2018. Excepting the capital region, all three other regions had a GDP per capita below the national average. Moreover, during the period under review, the poorer regions failed to improve their relative position.

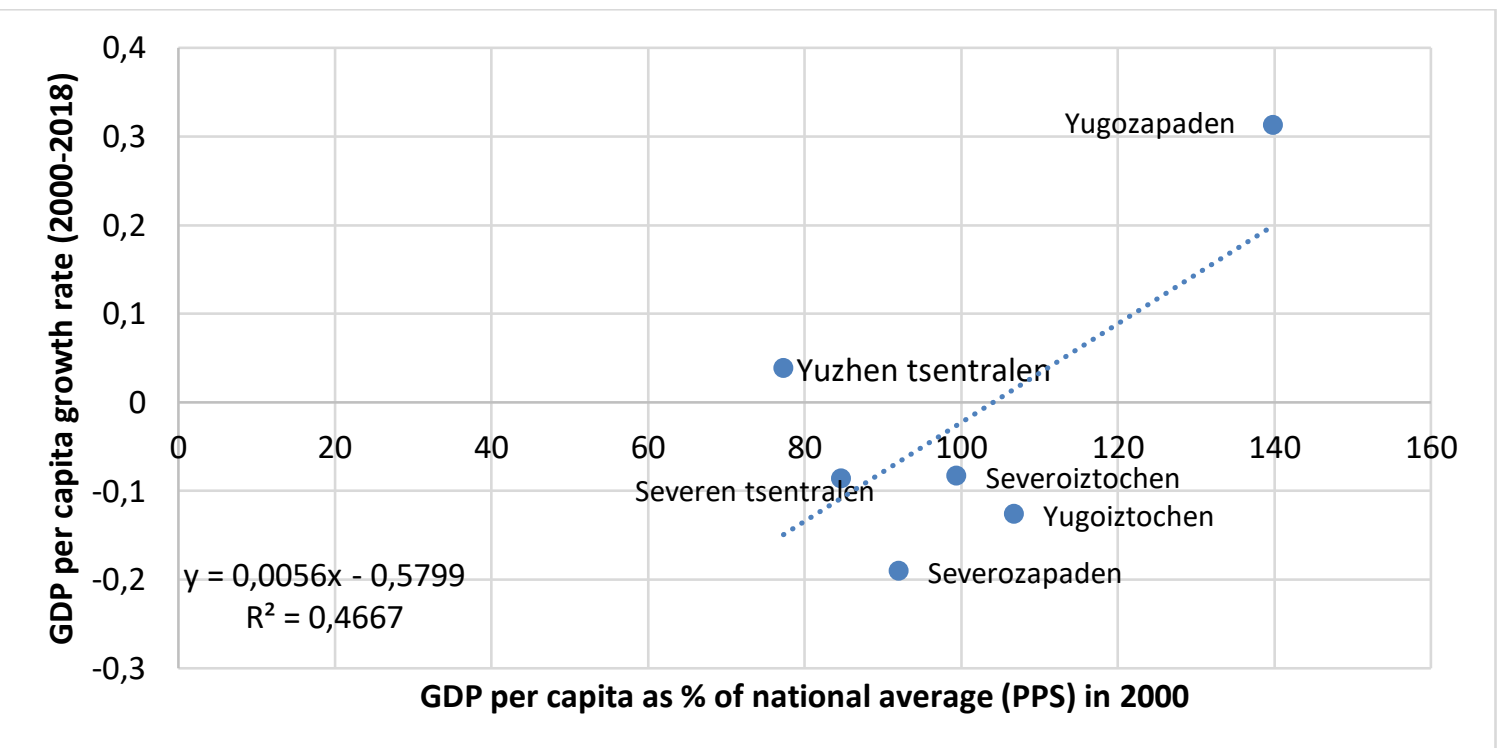

Figure 3. $\beta$-convergence in the NUTS 2 regions of Bulgaria

Source: Author's computation. 


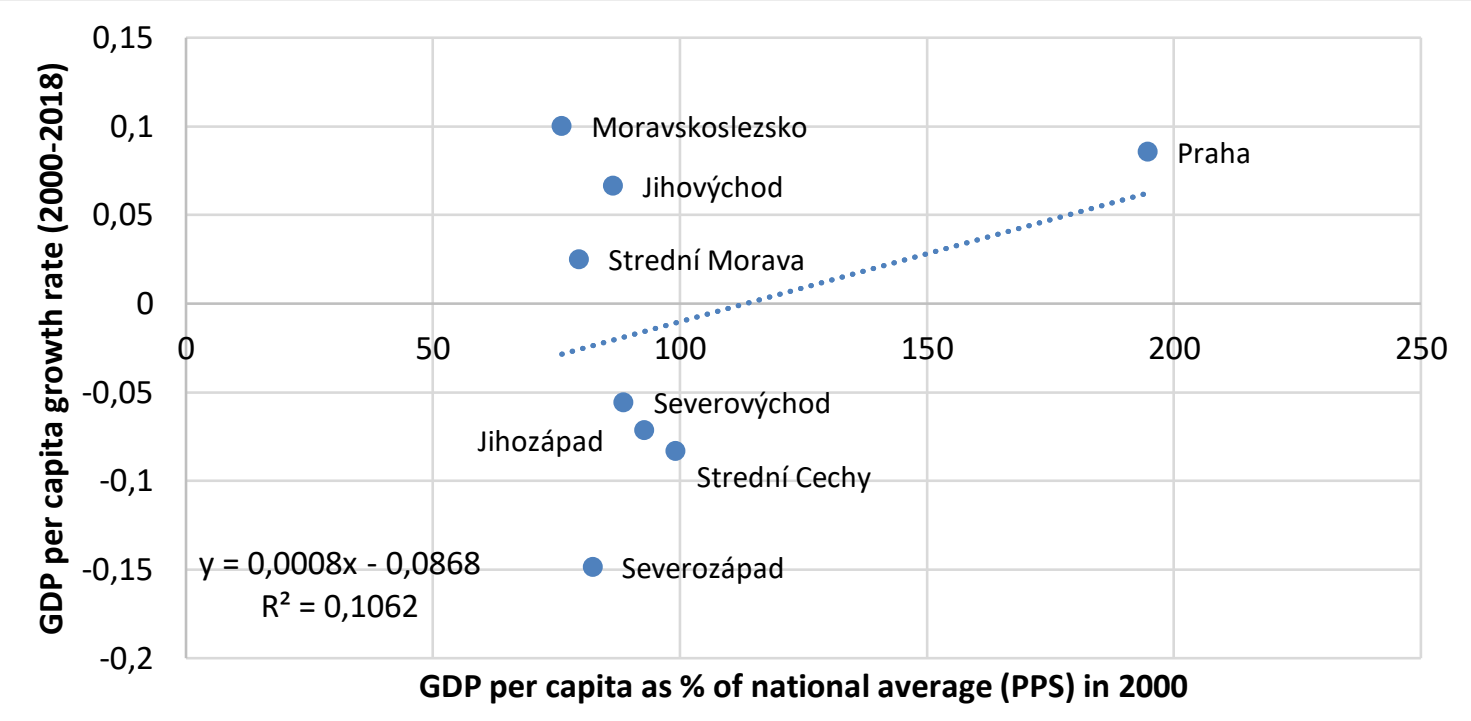

PICBE |

833

Figure 4. $\beta$-convergence in the NUTS 2 regions of Czech Republic

Source: Author's computation.

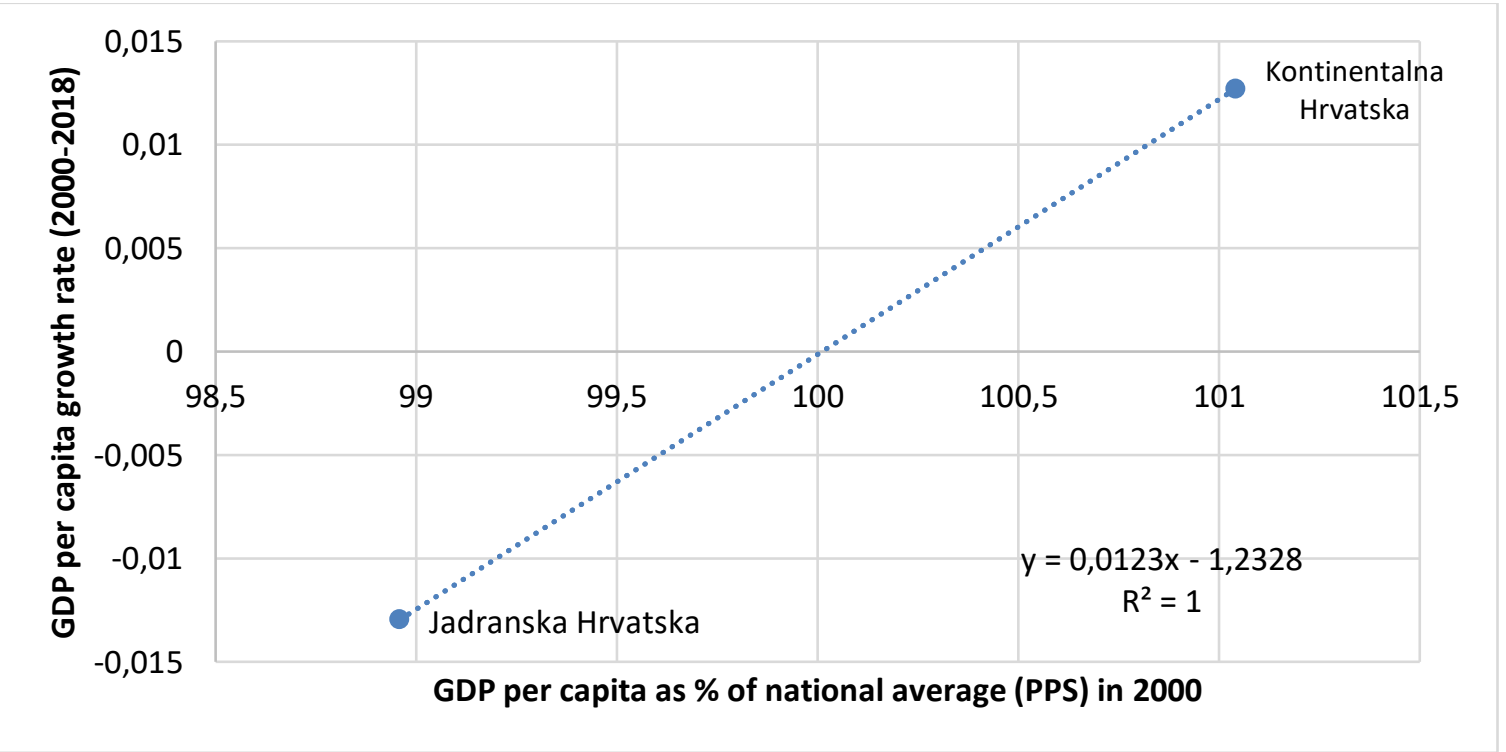

Figure 5. $\beta$-convergence in the NUTS 2 regions of Croatia

Source: Author's computation.

DOI: 10.2478/picbe-2021-0076, pp. 824-837, ISSN 2558-9652 |

Proceedings of the $15^{\text {th }}$ International Conference on Business Excellence 2021 


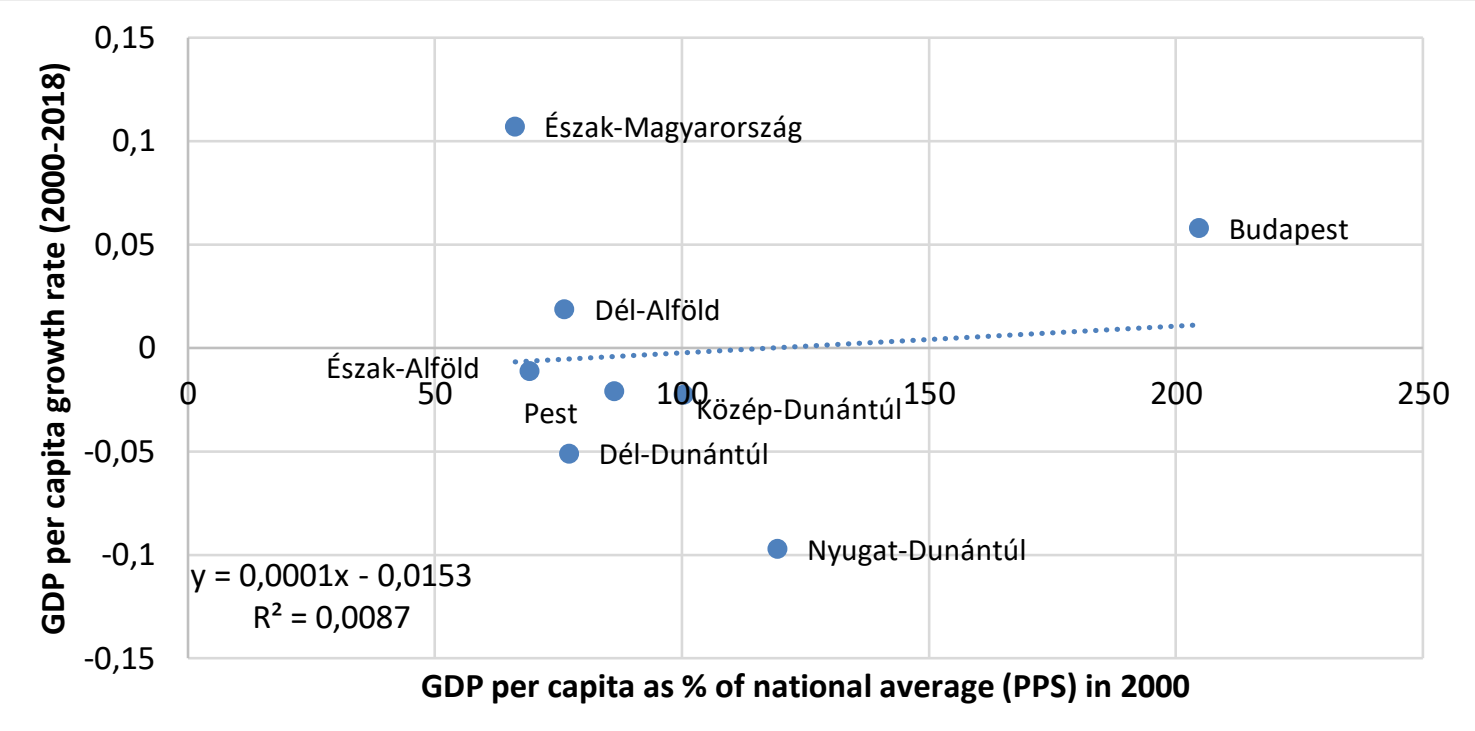

PICBE |

834

Figure 6. $\beta$-convergence in the NUTS 2 regions of Hungary

Source: Author's computation.

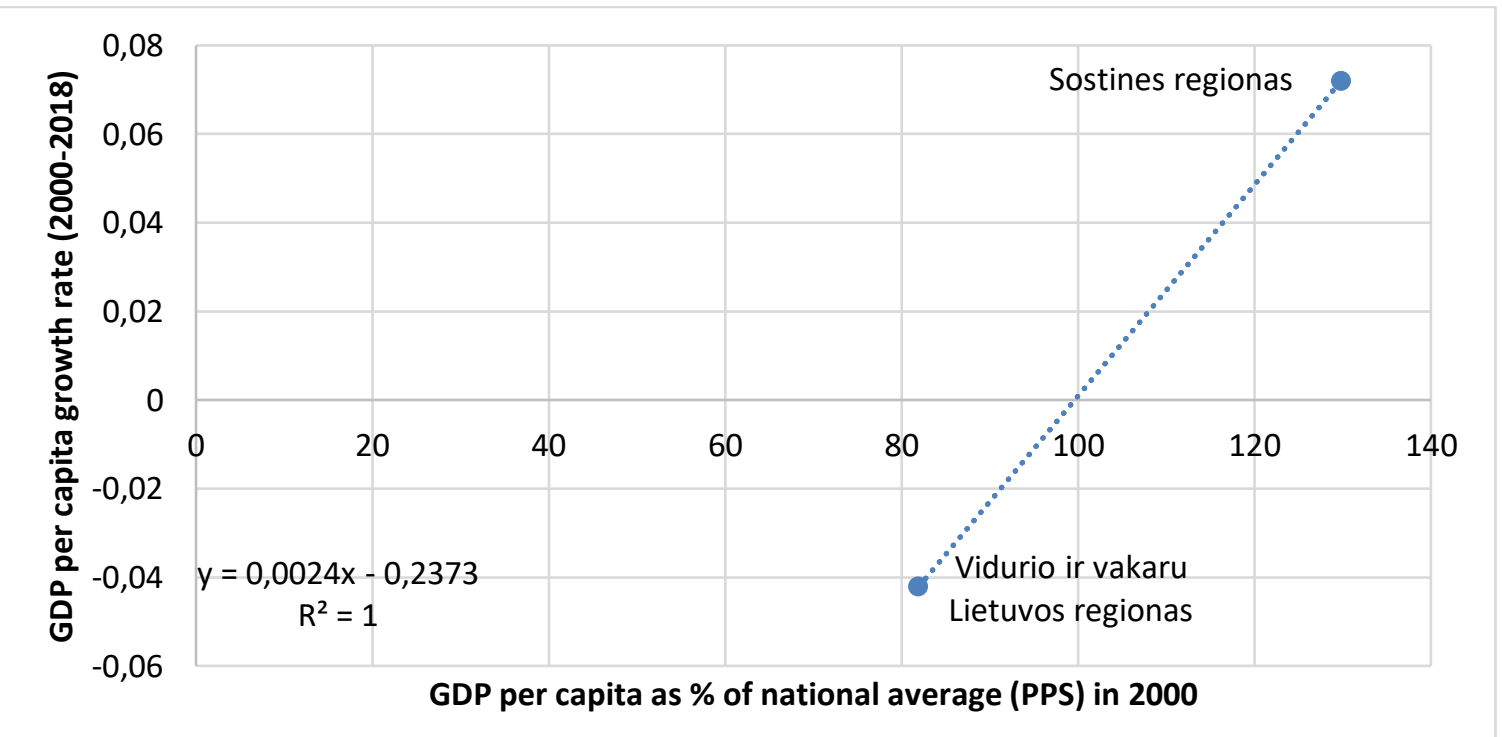

Figure 7. $\beta$-convergence in the NUTS 2 regions of Lithuania

Source: Author's computation 


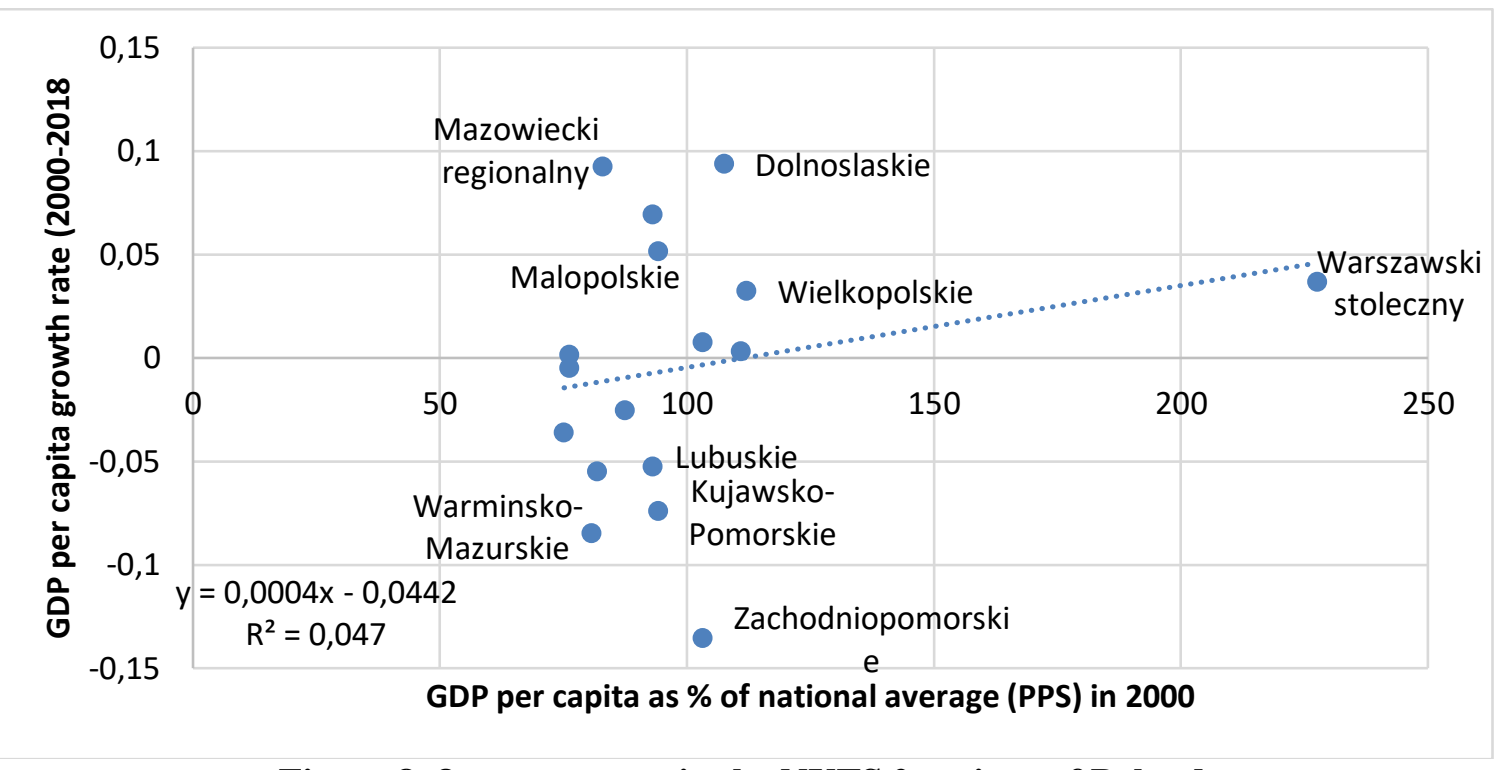

PICBE | 835

Figure 8. $\beta$-convergence in the NUTS 2 regions of Poland

Source: Author's computation.

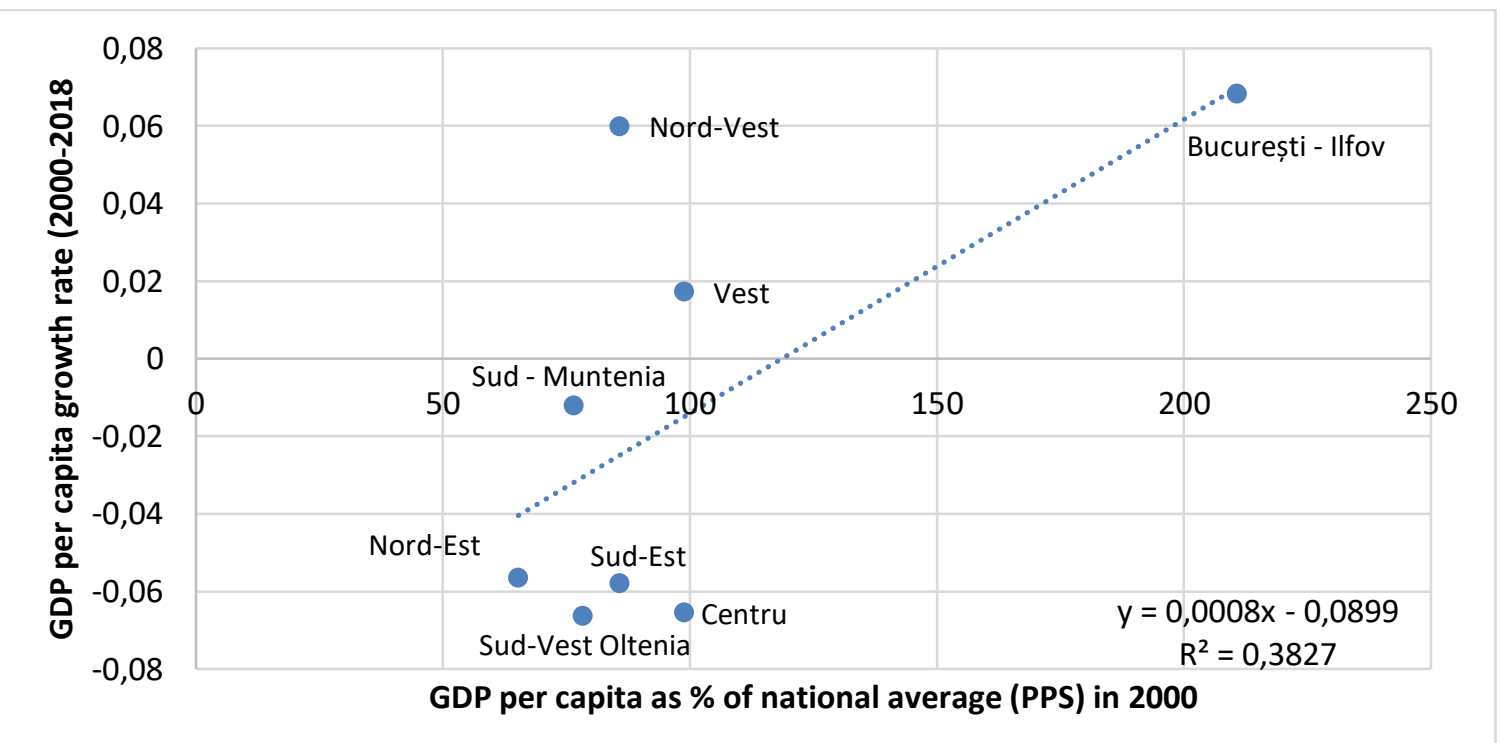

Figure 9. $\beta$-convergence in the NUTS 2 regions of Romania

Source: Author's computation. 


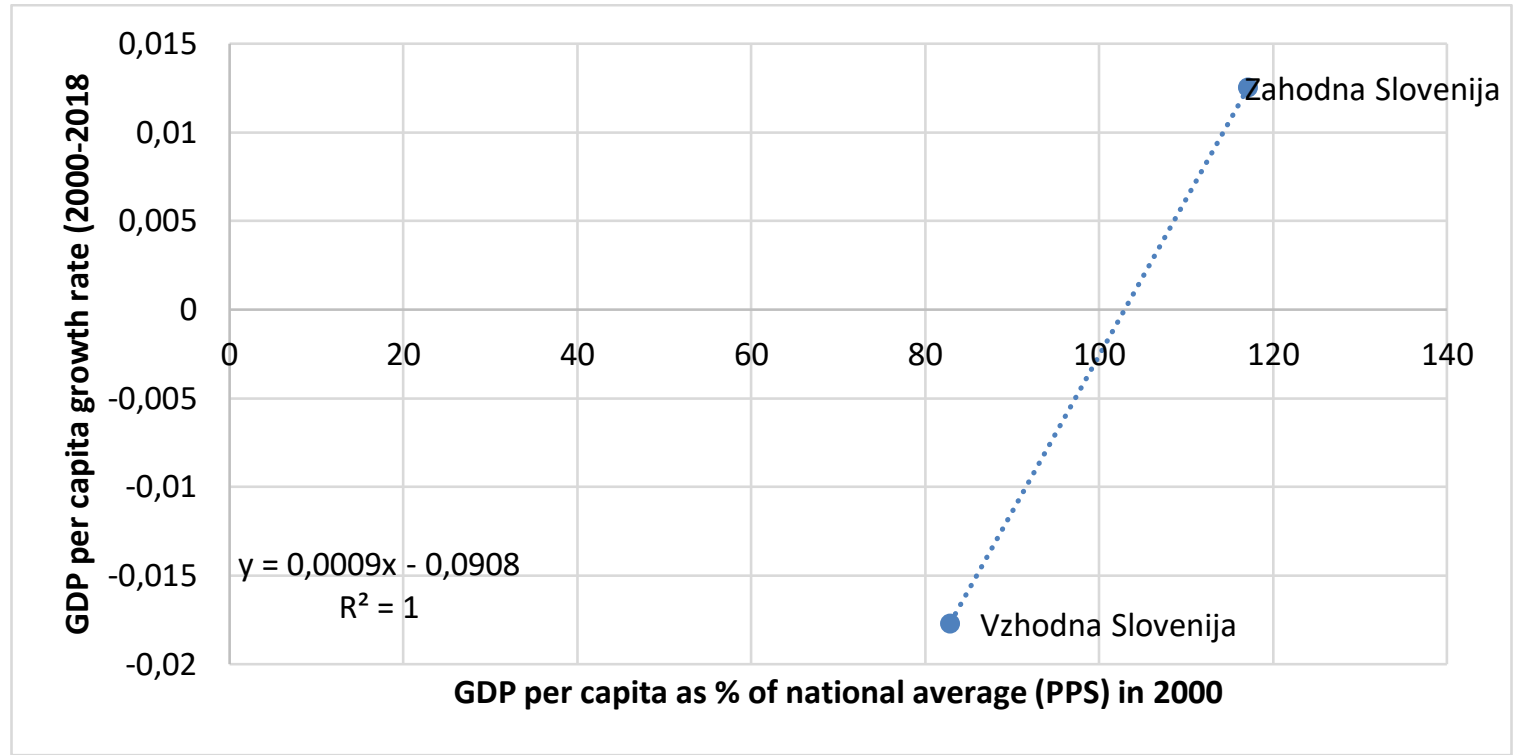

PICBE | 836

Figure 10. $\beta$-convergence in the NUTS 2 regions of Slovenia

Source: Author's computation.

\section{Conclusion}

The aim of this paper was to study real convergence in CEE, by conducting a comparative analysis of the evolution that took place between 2000 and 2018 at the national and regional levels. By using $\beta$-convergence, we have found evidence in favor of the neoclassical growth model assumptions, as the initially poorer CEE Members, for example, Romania and Bulgaria, experienced higher GDP per capita growth rates than the more developed ones (Slovenia, Czech Republic). The catching-up speed experienced by the CEE countries was on average $3.6 \%$ between 2000 and 2018. Moreover, the analysis of $\sigma$-convergence confirms that income disparities among the CEE decreased during the analyzed period. In contrast, the results of the cross-sectional regression indicate a weak relationship between the initial level of income and the subsequent growth rates for the CEE regions at NUTS 2 level. Moreover, the convergence speed at the regional level was only $1.6 \%$ between 2000 and 2018. The analysis of intra-national convergence/ divergence patterns suggests that the initially developed capital regions, with GDP per capita above the national average, consolidated their relative position. In contrast, the other territorial units have lagged behind the capital regions, recording GDP per capita below the national average. These results are in line with the conclusions of previous studies in the field of convergence, which suggest that CEE countries experience significant improvement in terms of GDP per capita. Furthermore, our study draws attention to the danger posed by the increase of intra-national divergences. The main limitation of the research derives from the limited period of time taken into consideration. In addition to this, the paper may be expanded by studying the influence of macroeconomic, social, or governance-related variables on economic growth in CEE.

\section{References}

Alcidi, C. Ferrer, J. N. Musmeci, R., Di Salvo, M., Pilati, M. (2018 b). Income Convergence in the EU: Within-country regional patterns, Centre for European Policy Studies (CEPS).

Alcidi, C., Ferrer, J. N., Di Salvo, M., Musmeci, R., Pilati, M. (2018 a). Income convergence in the EU: a tale of two speeds. Centre for European Policy Studies (CEPS). 
Barro, R. J. \& Sala-i-Martin, X. (1990). Economic Growth and Convergence across the United States. NBER Working Paper 3419, National Bureau of Economic Research.

Barro, R. J. \& Sala-i-Martin, X. (1992). Convergence, Journal of Political Economy, 100(2), 223-251.

Bourdin, S. (2015). National and regional trajectories of convergence and economic integration in Central and Eastern Europe, Canadian Journal of Regional Science / Revue canadienne des sciences régionales 38(1/3), 55-63.

Dobrinsky, R., \& Havlik, P. (2014). Economic Convergence and Structural Change: the Role of Transition and EU Accession, Research Report No. 395, The Vienna Institute for International Economic Studies.

Goecke, H., \& Hüther M. (2016). Regional Convergence in Europe, Intereconomics: Review of European Economic Policy, 51(3), 165-171.

Kolev, A. (2012). The impact of the recession in 2008-2009 on EU regional convergence, ECON Department Economic Studies Division. Luxembourg, European Investment Bank.

Magrini, S. (1999). The evolution of income disparities among the regions of the European Union, Regional Science and Urban Economics, 29(2), 257-281.

Matkowski, Z., Próchniak, M., \& Rapacki, R. (2016). Real Income Convergence between Central Eastern and Western Europe: Past, Present, and Prospects. $33^{\text {rd }}$ Centre for International Research on Economic Tendency Surveys Conference on Economic Tendency Surveys and Economic Policy (September 14 - September 17, 2016).

Rapacki, R., \& Próchniak, M. (2019). EU membership and economic growth: empirical evidence for the CEE countries, European Journal of Comparative Economics, 16(1), 3-40.

Rapacki, R., \& Próchniak, M. (2009). Real Beta and Sigma Convergence in 27 Transition Countries, 1990-2005, Post-Communist Economies, 21(3), 307-326.

Solow, R. M., (1956). A Contribution to the Theory of Economic Growth, The Quarterly Journal of Economics, 70(1), 65-94.

Swan, T. W. (1956). Economic growth and capital accumulation. Economic Record, 32(2), 334-361.

Vojinović, B., Acharya, S., \& Próchniak, M. (2009). Convergence Analysis among the Ten European Transition Economies, Hitotsubashi Journal of Economics, 50(2), 17-35. 